\title{
Practical Use of the Navigate Pain Application for the Assessment of the Area, Location, and Frequency of the Pain Location in Young Soccer Goalkeepers
}

\author{
by \\ Jarosław Muracki ${ }^{1}$, Martyna Kumorek ${ }^{1}$, Aleksandra Kisilewicz', \\ Beata Pożarowszczyk¹, Dennis Boye Larsen², Adam Kawczyński , Shellie Boudreau
}

Next to winning, minimizing injuries during training and matches is one of the primary goals of professional team sports games. Soreness and pain can be early indicators and risk factors for acute or long-term injuries. Monitoring pain intensity and duration, as well as potential sources, are useful for planning practices and can be effective means for preventing injury. The aim of this study was to assess the areas and locations of pain in young soccer goalkeepers during a training camp, and to differentiate the area and frequency between pain arising from the muscles $(M P)$, joints $(J P)$, or as a result of an impact (IP). Recordings of the MP, JP, and IP location along with the area were performed using digital body mapping software (Navigate Pain Android app, Aalborg University, Denmark) installed on a tablet personal computer at the end of each training day across a 5-day training camp. There was a significant difference in the area between the three types of pain $(p<0.001)$. The post hoc analysis revealed statistically significant differences between the pixel areas of IP versus JP $(p<0.001)$, IP versus MP $(p<0.001)$, and JP versus MP $(p<0.001)$. There was no significant time-effect for the IP area between 1-5 days of training $(p=0.610)$, neither for MP $(p=0.118)$ or JP $(p=0.797)$ and no significant difference for all three pain areas between the front and the back side of the body. The body regions most often reported for MP were thighs, while for JP they were groin and hips, and for IP the hips, shoulders, and forearms were most frequently indicated. This is the first study to map and report the pain distribution associated with training across a 5-day training camp in soccer goalkeepers, and these findings emphasize the value of using digital pain drawings clinically as well as for monitoring the health status of soccer players.

Key words: pain, navigate pain, soccer, goalkeepers training.

\section{Introduction}

In professional soccer, muscle injuries represent $20-46 \%$ of all injuries (Hägglund et al., 2005 ) and $18-23 \%$ at an amateur level (Chamari et al., 2012). The National Collegiate Athletic Association (NCAA)'s Injury Surveillance System, which is a reliable database for professional athletes, makes it clear that soccer has the highest injury rates for practices and games (9.6 and 35.9 injuries per 1,000 athletes, respectively) (Hootman et al., 2007).
For nine consecutive seasons, Kristenson and colleagues (2013) recorded injuries of 1,401 players from 26 soccer clubs and revealed that 6,140 injuries occurred during 797,389 hours of training sessions and matches. This approximates one injury for every 130 hours of training and/or match time. According to these data, it can be estimated that a soccer player who trains and competes for 10 hours per week would sustain an injury every 13 weeks. Similar results were

1 - Department of Paralympic Sport, Faculty of Sports Sciences, University School of Physical Education in Wroclaw, Poland.

2 - Department of Health Science and Technology, CNAP, SMI® Aalborg University, Denmark. 
obtained by Hägglund et al. (2003) who, during the 2001 season, demonstrated 0.78 injuries per 100 hours of total exposure in a cohort of male soccer players.

Kirkendall and Dvorak (2010) reported that injuries in soccer players commonly occurred in the lower (67.7\%) and upper limbs (13.4\%). In the lower limbs, muscle injuries were most common (92\%) and typically involved hamstrings, adductors, quadriceps, and calves (Ekstrand et al., 2011). An analysis of physical characteristics and capacities including body height and mass, body composition, flexibility, leg extension power, jump height, peak $\mathrm{O}_{2}$ uptake, joint stability, as well as history of previous injury, showed that age (odds ratio equals 1.1 per year) and previous traumas (odds ratio equals 4.6 for knee and 5.3 for ankle sprains, respectively) were risk factors for injuries among elite soccer players (Arnason et al., 2004).

During training and matches, soccer goalkeepers perform dynamic movements such as quick changes of direction, dives, jumps, throwing, and kicking, which can become sources of muscle or joint injuries. In addition, goalkeepers are exposed to many one-on-one defensive situations, such as shot stopping and tackling. As a result, soccer goalkeepers can collide with another player, the ball, the goal post, and the ground (Knoop et al., 2013) and sustain an impact injury. An obvious goal of training is to simulate game situations while minimizing the sources of injuries and avoiding overtraining. Overtraining can lead to excessive pain, fatigue, loss of optimal physical condition, and an increase in the risk of injury (Carfagno and Hendrix, 2014). The goals of training and the consequences of losing a goalkeeper due to pain or injuries prior to a match suggest that monitoring those two factors may be a smart starting point for maintaining a healthy and competitive team.

Monitoring overtraining, fatigue, pain, and acute injuries is far from trivial. With respect to pain, there are a number of questionnaires for pain assessment. Examples of these are the Sports Inventory for Pain, the Wong-Baker FACES Rating Scale, the 0-10 Numeric Pain Rating Scale, the Visual Analogue Scale, and the Verbal Pain Intensity Scale. Many pain assessment questionnaires or scales place little emphasis on the location, area, and distribution of the pain, discomfort or injury. Notably, there is a lack of information about how pain and injury may accumulate within or across several soccer training sessions and matches.

Digital pain drawings are a modern pain assessment method to record the location and distribution of pain. Symptoms or discomforts, such as the area and location of different types of pain, can be easily recorded, and a quantification of the area (expressed in pixels) and changes can be tracked across training days. Previous studies of digital pain drawings have shown high reliability and consistency between pain records as assessed on both male and female body schemas (Boudreau et al., 2016; Egsgaard et al., 2016).

The aim of this study was to determine the areas and locations of pain experienced in young goalkeepers attending a 5-day training camp. The goal was to differentiate between the area and locations of pain arising from the muscles (MP - Muscle Pain), from the joints (JP) or as a result of an impact (IP). Such information would allow for a more detailed understanding of where soccer goalkeepers are likely to report pain throughout a period of training. These data may help to qualify different sources of pain and injuries while achieving a better visualization of a soccer goalkeeper experience of pain and discomfort. Furthermore, the findings of this study may help coaches and goalkeepers prevent avoidable injuries.

\section{Methods}

\section{Participants}

Twenty-four healthy male goalkeepers (age: $16.7 \pm 0.67$ years, body height: $175.6 \pm 5.4 \mathrm{~cm}$, body mass: $65 \pm 5 \mathrm{~kg}$ ) were included in the study, all having at least 4 years of training experience and, at the time of the study, were playing in the Polish elite junior leagues. The goalkeepers were required to have a current medical examination before the study commenced. Exclusion criteria were: (1) current injury or other illness eliminating players from training and competition; (2) history of severe injuries currently causing pain symptoms; and (3) consumption/abuse of painkillers. Prior to the beginning of the study, all participants provided informed written consent. The study was approved by the local ethics committee of the 
University School of Physical Education in Wroclaw and conducted in accordance with the Declaration of Helsinki.

\section{Experimental design}

The study was conducted during a preplanned 5-day training camp. Information on the pain area, location and distribution of MP, JP and IP was collected on training days 1 - 5. The training camp aimed to improve technical and tactical behavior of soccer goalkeepers. Before starting the training camp, anthropometric measurements (body height and mass) were collected, and on Day 0, all participants performed their first report of MP, JP and IP using the Navigate Pain application (app). On each subsequent day (1-5), goalkeepers attended two 90-min training sessions (the first one at 11:00 $\mathrm{AM}$, and the second one at 5:00 PM). Each training session started with a 20-min warm-up, followed by goalkeeping exercises. After the end of the second training session each day, participants were asked to indicate areas and types of pain on a digital body schema, if they had any, using a digital body mapping software app. The time between training sessions was 4.5 hours of rest. No external physical therapy nor other methods to enhance recovery were applied.

Recordings of Muscle Pain, Joint Pain and Pain from Impact

Recordings of the pain location and area were performed using the Navigate Pain Android app (Aalborg University, Denmark) installed on a tablet personal computer (Lenovo Tab 10 TB$\mathrm{X} 103 \mathrm{~F})$. Participants were asked to draw the area and location of MP, JP or IP. The drawings were performed on a 2D male body outline representing the anterior and posterior parts of the body. The 2D image itself did not rotate, and the perspective remained constant during data collection. Participants used an S-pen or a finger to draw on the touch-screen interface, which both had a high-level of agreement and can be considered comparable to pain areas drawn with a traditional pen and paper (Boudreau et al., 2017).

Participants could choose from three colors to express MP, JP, and IP. Blue, grey, and red were used to represent MP, JP, and IP, respectively. Participants were asked to qualify pain as MP when it was localized only within the muscle structure and it was not caused by direct impact, although technically that could also be a source of MP. Reporting of JP referred to pain stemming from the joint area and not directly related to an impact, yet it was considered as a result of external or internal loads during joint movement. Participants were also informed that IP should be reported when pain originated from a deliberate or an unintended contact with an opponent or a team partner, a ball hit, a fall on the ground or from a hit or knock on the goal structure.

\section{Quantification of pain area and location}

MP, JP and IP were reported using separate digital pain drawings for both the anterior and posterior views, if present. Using the Navigate Pain app, the areas of MP, JP, and IP were automatically extracted and expressed as a total number of pixels. Each digital pain drawing was then reviewed, and the pain locations were recorded offline for further analysis.

The anterior and posterior body charts were divided into zones of interest, reflecting body regions specific for each pain type. The zones of interest were predetermined and based on the observations coming from our previous pilot studies. For the MP charts, the division was based on large muscle groups (Figure 1a). For the JP charts, it reflected the joints of the body (Figure $1 b)$. For IP, the chart was divided into body zones covering large surfaces and extracting most crucial regions like hands and fingers, knees, hips, arms and forearms, shanks and feet, head, and neck (Figure 1c).

\section{Goalkeeping exercise}

During training sessions, goalkeepers practiced exercises presented in Figure 2, involving shot stopping (Figure 2a and 2d), crosses interceptions and throwing (Figure 2b), defending in 1v1 situations and passing (Figure 2c and $2 \mathrm{~d}$ ).

\section{Statistical analysis}

Statistical analysis was performed using the Statistical Package for Social Sciences (SPSS, IBM). To investigate the location and extent of the three types of common pain reported by goalkeepers (MP, JP and IP), the total number of pixels for drawn areas of pain was extracted. Normality of the residuals was tested using the Shapiro-Wilk test for normality. The pixel data were subjected to a Friedman repeated-measures analysis of variance (RM ANOVA) on ranks 
(within-subjects factor: pain type). The Friedman RM ANOVA was also performed to investigate time-effect between 5 training days for each type of pain. Wilcoxon signed-rank tests were performed on the pixel data of different types of pain (IP vs. JP, IP vs. MP, MP vs. JP) to determine which types of pain significantly differed. Furthermore, to explore the change in the total area of pain from day 1 to 5 of the training camp, pixel data were subjected to the Wilcoxon signedrank test. To investigate whether the pain area differed between the front and the back of the body, Wilcoxon signed-rank tests were performed for all three pain types (front vs. back total pixel count). Bonferroni correction was applied where appropriate. Data are presented as mean \pm standard error of the mean, unless otherwise stated.

The Cochran's $Q$ test was employed to test if the proportion of reports of pain in one area (for instance impact pain in the head and neck) was significantly different over the days. To test this, the presence of pain in an area, characterized as muscle, joint, or impact pain was categorized as a " 1 ", whereas the absence was denoted as a " 0 ". Sample size adequacy was tested using the $\chi^{2-}$ distribution approximation method. A summary of the different pain areas dichotomized for each type of pain is shown in Table 1. Statistical significance for all analyses was accepted at $p<$ 0.05 .

\section{Results}

In general, goalkeepers reported at least one of the three pain types (Figure 3). Superimposed overlays of the digital pain drawings, as shown in Table 1, present heterogeneous reporting of MP, JP and IP (Figure 4 a-f).

Muscle, Joint, and Impact Pain Area

The Shapiro-Wilk test revealed that data were not normally distributed $(p<0.05)$. The Friedman RM ANOVA on ranks revealed a significant difference between the three types of pain $(p<0.001)$. The post hoc analysis indicated statistically significant differences between the pixel areas of IP vs. JP $(p<0.001)$, IP vs. MP ( $p<$ $0.001)$, and JP vs. MP $(p<0.001)$.

The Friedman one-way RM ANOVA showed no significant time-effect for the MP $(p=$ $0.118)$ area between $1-5$ days of training $(p=0.610)$, nor for JP $(p=0.797)$ nor IP $(p=0.610)$. The Wilcoxon signed-rank test revealed no significant difference for all three pain areas between the front and the back side of the body $(p=0.615, p=$ 0.234 , and $p=0.977$ for $\mathrm{MP}, \mathrm{JP}$, and IP, respectively).

Muscle, Joint, and Impact Pain Location

The zones of interest most often reported for MP were thighs (21 participants), for JP they were groin and hips (7 participants), and for IP they were hips, shoulders, and forearms (16 participants for each area) (Table 1).

The Cochran's $Q$ test revealed that the proportion of individuals reporting MP across days did not change significantly over time for any area assessed. A tendency was seen for the shoulders and the neck (zone 1), $\chi^{2}(4)=8.6, p=$ 0.07 , and for the glutes (zone 5), $\chi^{2}(4)=8.6, p=$ 0.07 .

IP changed significantly at the level of the upper legs, $\chi^{2}(4)=10.46, p=0.03$, with a tendency at the lower legs and feet, $\chi^{2}(4)=9.25$, $p=0.055$. Post hoc analysis only showed a tendency towards difference between day 1 and day $5(p=0.085$, corrected), and between day 4 and day 5 ( $p=0.085$, corrected).

Lastly, the presence of JP changed across days in areas determined as "others", $\chi^{2}(4)=10.86, p=$ 0.028 . Post hoc analysis showed that day 5 vs. day 2 had significantly higher frequency of pain presence reports ( $p=0.028$, corrected).

\section{Discussion}

This is the first study to report the location and the area of MP, JP, and IP in youth soccer goalkeepers throughout a 5-day training period. The goal of the study was to differentiate between pain arising from the muscles (MP Muscle Pain), the joints (JP - Joint Pain), or as a result of an impact (IP - Impact Pain) in terms of both the location and frequency of reports. Our second goal was to introduce digital body mapping software for the assessment of musculoskeletal pain in professional athletes. The current study found a significant difference in the areas of pain originating from physical contact, muscle, and joint overloading or injury. Although goalkeepers reported no pain at baseline, following the first day of training there were no significant changes in the overall area of MP, JP, and IP across the five days of training (Figure 5). 

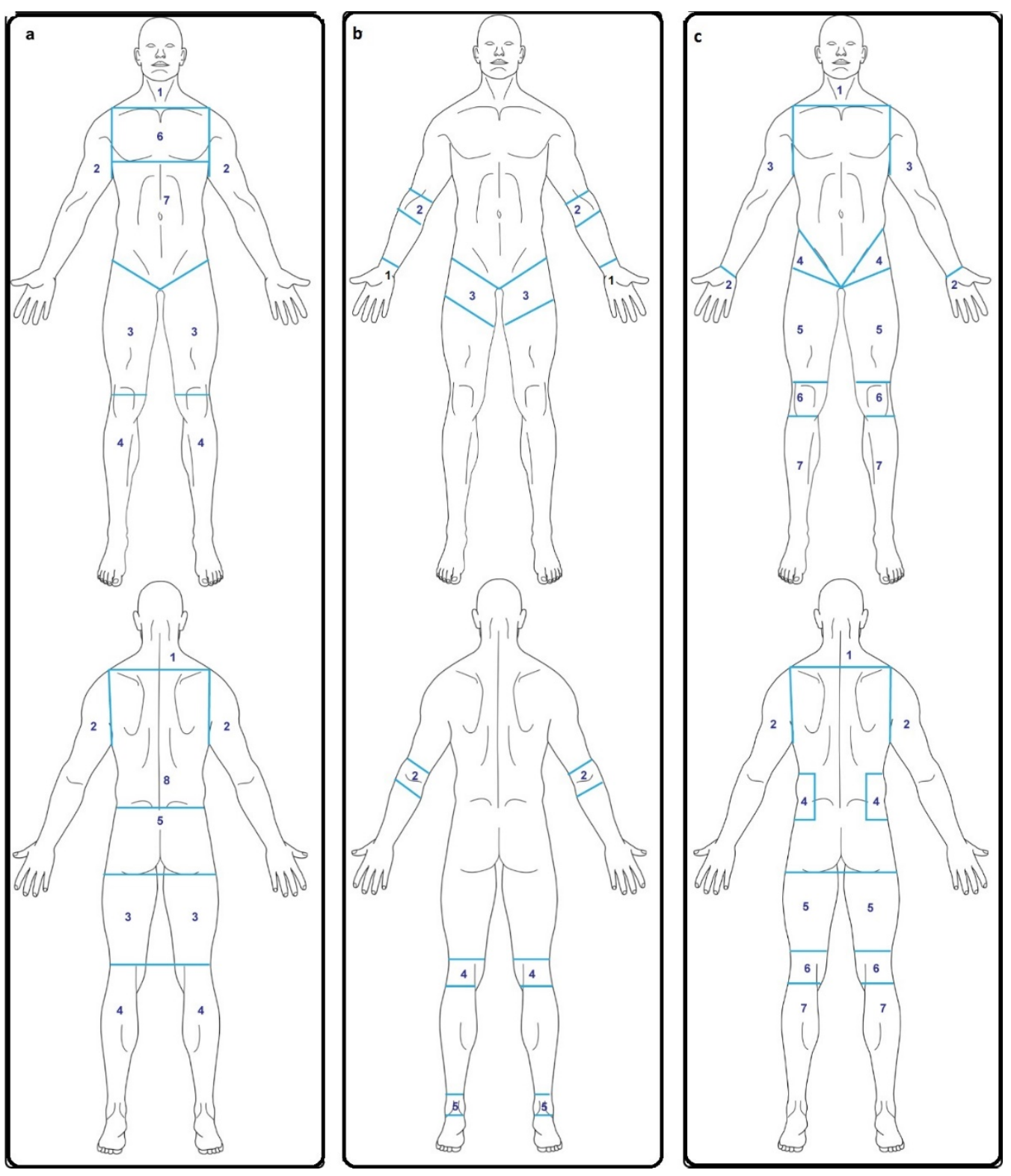

Figure 1

Specific zones of interest as outlined on the anterior and posterior parts of the digital body chart used to determine the frequency of (a) muscle pain with 1: neck and shoulders; 2: upper limbs; 3: thighs; 4: shanks; 5: rear; 6: chest; 7: abdomen; 8: back (b) joint pain with 1: hands and wrists; 2: elbows; 3: groin; 4: knees; 5: ankles; Other: shoulder, neck and (c) impact pain with 1: head and neck; 2: hands and fingers; 3 : forearms and arms; 4: hips; 5: thighs; 6: knees; 7: shanks and feet; Others: abdomen, chest; across the 5 training days. 


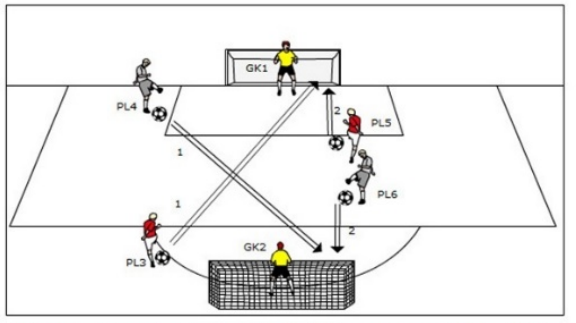
a) Shoot stopping exercise: 1 - Player (PL) 3 and 4 shoot, goalkeeper (GK) 1 and 2 defend
2- PL 5 and 6 shoot the deflected ball or the second ball

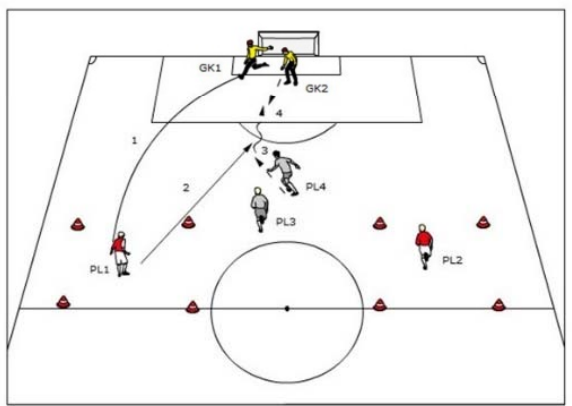

c) Ivl and passing exercise: 1. GK 1 kicks the ball to pass it to PL 1 (or to PL 2).

2. PL 1 (or PL 2) receives the ball and passes at the goal direction.
3. PL 4 (or PL 3) receives the ball and attacks the goal in 1 lv duel with GK 2 (or GK1).

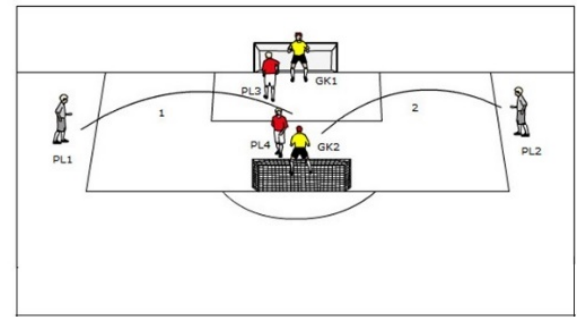

b) Crosses interception exercise: 1- PL 1 crosses for GK 1 or 2 PL 3 and 4 try to score or to prevent GX 3 interention After two situations PL 2 starts the next action with crossing

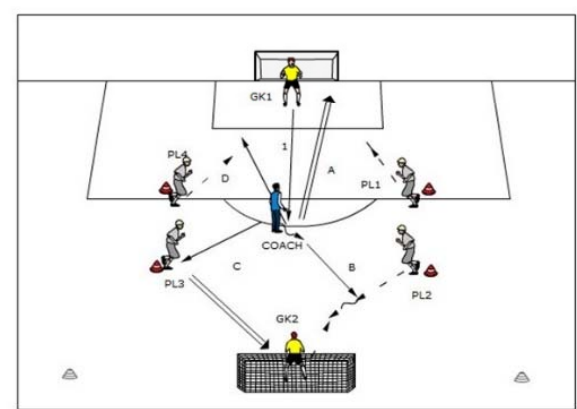

d) Shot stopping and lv1 exercise : 1 - GK1 passes the ball to the coach

Coach creates one of the following situations:

A-Coach shoots, PL1 runs to shoot the ball if GK1 deflects when defending the goal
B-Coach passes the ball to the PL2 and he goes into lv1 duel with GK2 who tries to defend the goal passes the ball to the PL2 2 and he goes into $1 \mathrm{l} 1 \mathrm{~d}$ duel with $\mathrm{GK} 2$ who this

C-Coach passes the ball to the PL 3 and he shoots and GK2 defends the goal
D- Coach passes the ball at the goal direction, the GK1 and the PL4 compete to get the ball first

Figure 2

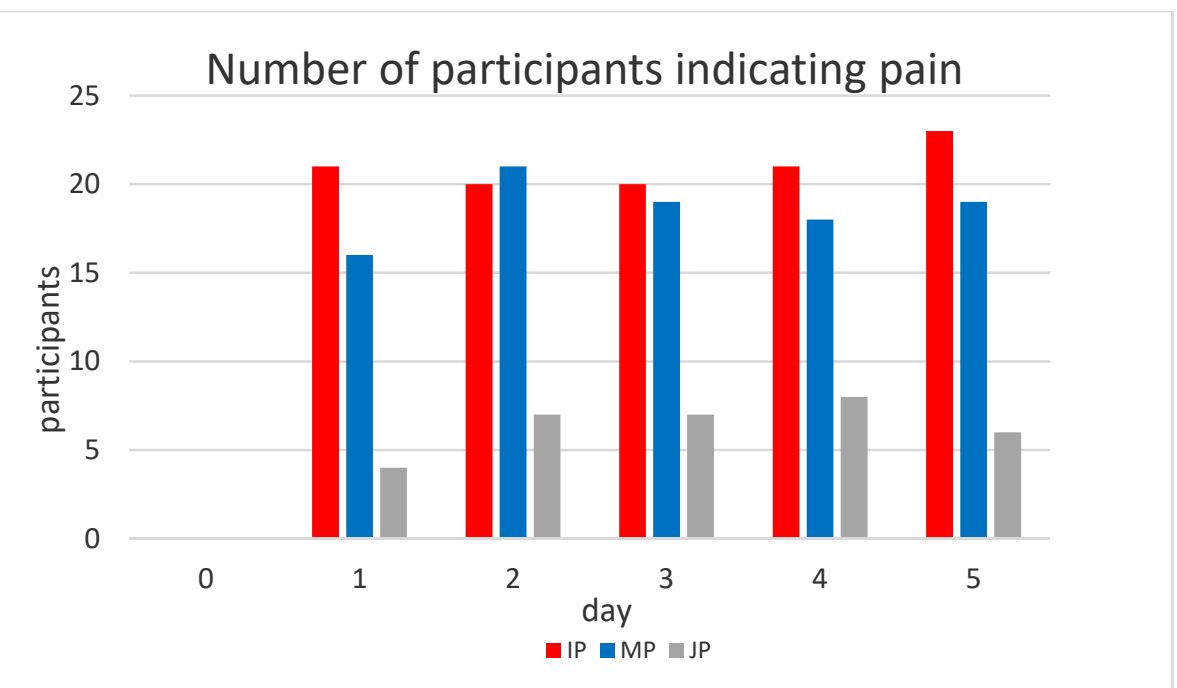

Figure 3

The number of individuals reporting impact pain (IP), muscle pain (MP), and joint pain $(J P)$ over the 5-day training period. 


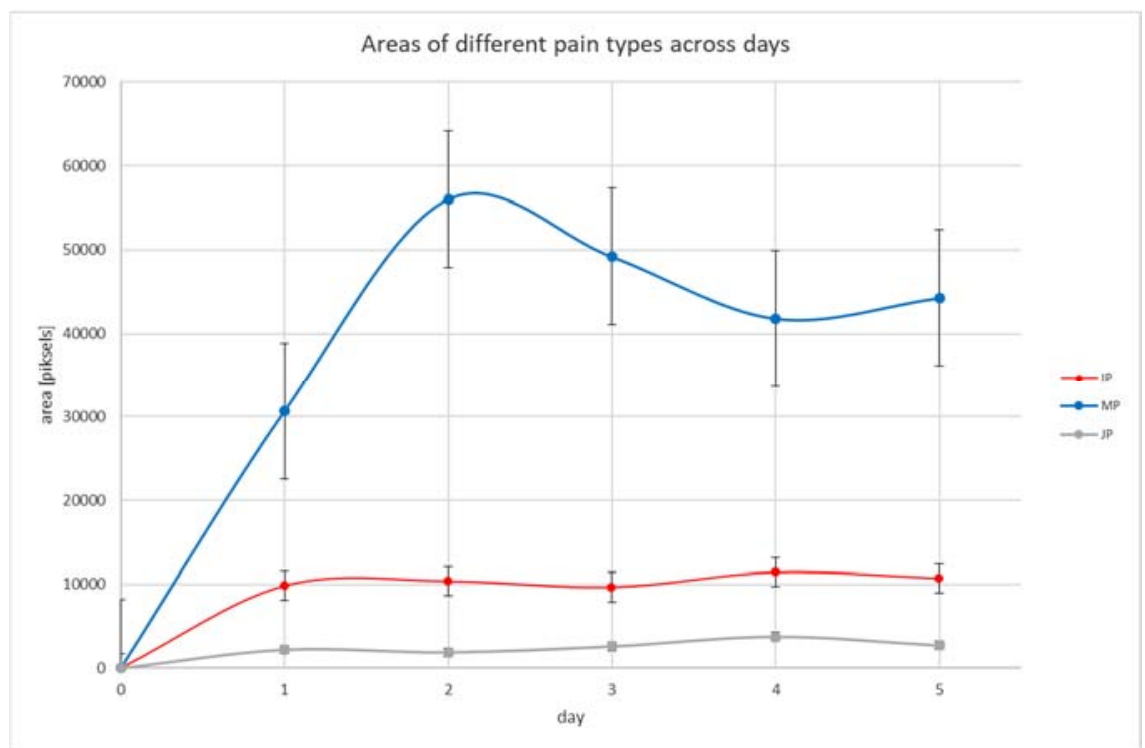

Figure 4

The total area muscle pain (MP), joint pain (JP), and impact pain (IP) across the 5-day training period showing a relatively larger area of muscle pain. Data are presented as mean \pm SEM.

Table 1

The distribution of muscle pain, joint pain, and impact pain reported by soccer players in each zone of interest as taken from the anterior and posterior body charts for all 5 training days. ${ }^{*} \chi^{2}(p=0.005)$.

\begin{tabular}{|c|c|c|c|c|c|c|c|c|}
\hline \multicolumn{9}{|c|}{ A) MUSCLE PAIN } \\
\hline & $\begin{array}{l}\text { schoulders } \\
\text { and neck }\end{array}$ & upper limb & upper leg & $\begin{array}{c}\text { lower } \\
\text { leg }\end{array}$ & gluts & chest & abdomen & back \\
\hline $\begin{array}{c}\text { SUM } \\
\text { OUT OF } \\
24\end{array}$ & 7 & 8 & 21 & 9 & 7 & 8 & 5 & 5 \\
\hline $\begin{array}{l}\% \text { OF } \\
\text { ALL }\end{array}$ & $29 \% *$ & $33 \%$ & $88 \% *$ & $38 \%$ & $29 \% *$ & $33 \%$ & $21 \% *$ & $21 \% *$ \\
\hline & $\begin{array}{c}\text { hands and } \\
\text { wrist }\end{array}$ & elbows & $\begin{array}{l}\text { B) JO } \\
\text { groin and } \\
\text { hip }\end{array}$ & $\begin{array}{l}\text { Г PAIN } \\
\text { knees }\end{array}$ & ankles & \multicolumn{3}{|c|}{ other (sholulder, back, neck) } \\
\hline $\begin{array}{c}\text { SUM } \\
\text { OUT OF } \\
24\end{array}$ & 4 & 4 & 7 & 5 & 4 & \multicolumn{3}{|c|}{4} \\
\hline $\begin{array}{l}\% \text { OF } \\
\text { ALL }\end{array}$ & $17 \% *$ & $17 \% *$ & $29 \% *$ & $21 \% *$ & $17 \% *$ & & $17 \% *$ & \\
\hline \multicolumn{9}{|c|}{ C) IMPACT PAIN } \\
\hline & $\begin{array}{l}\text { head and } \\
\text { neck }\end{array}$ & $\begin{array}{l}\text { hands } \\
\text { including } \\
\text { fingers }\end{array}$ & $\begin{array}{l}\text { arm and } \\
\text { forearm }\end{array}$ & hip & $\begin{array}{l}\text { upper } \\
\text { leg }\end{array}$ & $\begin{array}{c}\text { knee } \\
\mathrm{s}\end{array}$ & $\begin{array}{l}\text { lower leg } \\
\text { and feet }\end{array}$ & $\begin{array}{c}\text { other } \\
\text { (shoulder, } \\
\text { gluts, back, } \\
\text { chest, } \\
\text { abdomen) }\end{array}$ \\
\hline $\begin{array}{c}\text { SUM } \\
\text { OUT OF } \\
24\end{array}$ & 1 & 5 & 16 & 16 & 10 & 14 & 5 & 9 \\
\hline $\begin{array}{l}\% \text { OF } \\
\text { ALL }\end{array}$ & $4 \% *$ & $21 \% *$ & $67 \%$ & $67 \%$ & $42 \%$ & $58 \%$ & $21 \% *$ & $38 \%$ \\
\hline
\end{tabular}




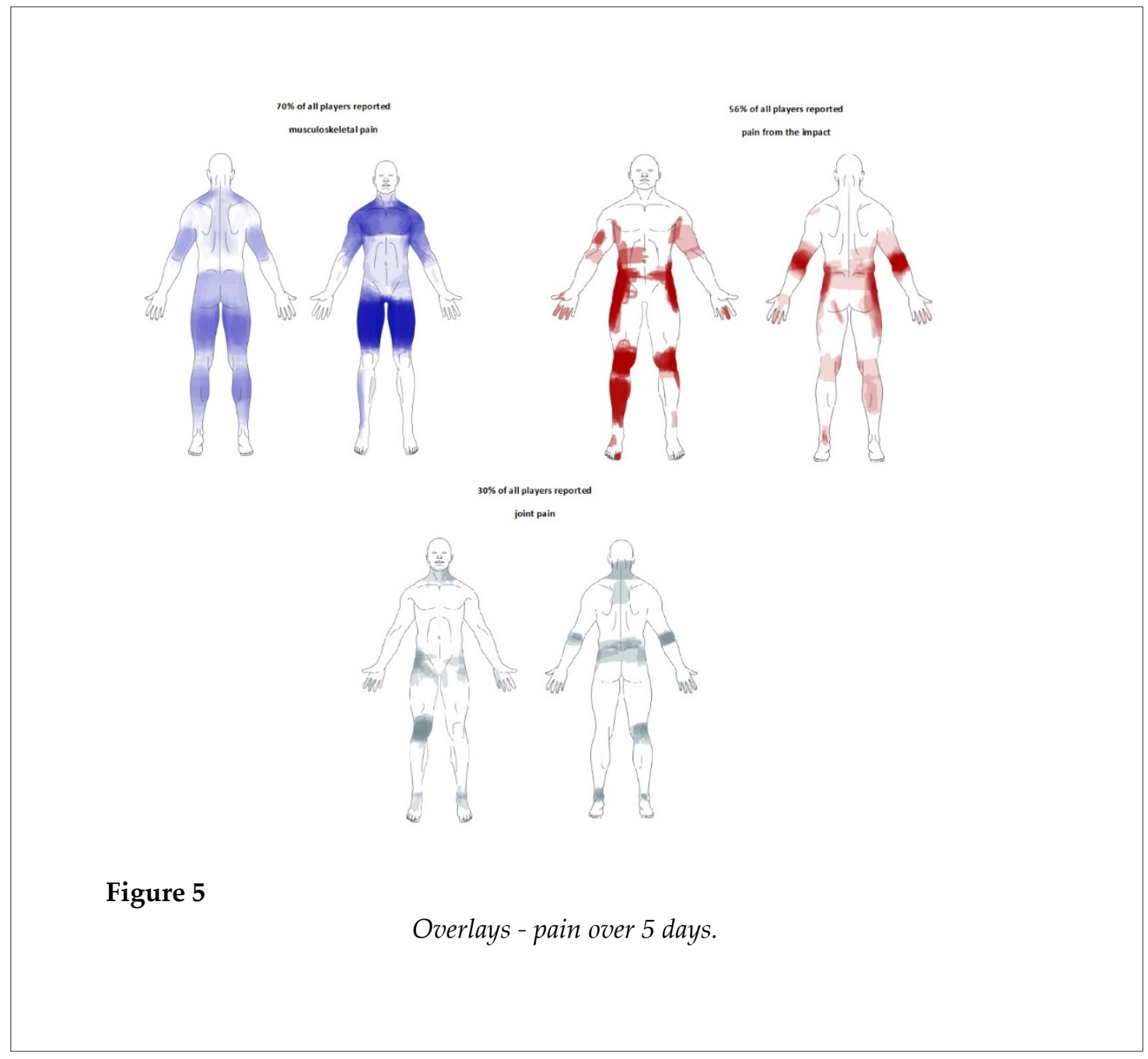

This result may be explained by changes in the frequency of the pain location across days.

According to youth goalkeepers, MP, JP, and IP occurred after the first training day, and the overall area of those reports was maintained across the 5-day training period. This means that injuries sustained on the first day had little time for recovery and there was a tendency for an increase on the last day. The body regions most often reported for IP were hips, shoulders, and forearms, and for JP they were the groin and the hips. The goalkeepers' pain reports were considered a result of repetitive daily training loads, together with bruises and contusions resulting from impact and overloading joint structures. Reported JP by goalkeepers could potentially be used to indicate which joints are most exposed to injury during training, and thus may guide rehabilitation and care. Our findings show that young goalkeepers often suffer from different types of pain in the groin area, which is fairly consistent with Ekstrand and colleagues (2004), who demonstrated that hip and groin injuries constituted up to $20 \%$ of all injuries and were a major problem for soccer players in general.

An interesting study conducted by Drew at al. (2016) on 66 professional Australian soccer players showed that groin pain experienced by players was an even larger issue than the published incidence rates implied. A prior groin injury almost doubled the risk of developing a subsequent groin injury, and playing at a higher level almost tripled the risk (Hölmich et al., 2015). Although the mechanisms contributing to groin injuries are less clear, studies indicate an imbalance in hip adduction-abduction muscles, i.e. a decrease in the hip-adductors and an increase in eccentric hip-abduction strength, as the main reason for hip and groin injuries (Jensen 
et al., 2014).

MP or muscle soreness was present in a wide range of muscle groups and covered a large area of the body. The muscle pain reported in this study likely reflected delayed onset muscle soreness (DOMS). In general, DOMS develops after physical activity where the predominant type of contractions is eccentric (Chatzinikolaou et al., 2010). Activities performed by goalkeepers, such as frequent and fast changes of directions, ball kicking, maximal jumps, or direct contacts with opposing players, involve many eccentric muscle contractions (Osgnach et al., 2010). Young goalkeepers most often reported MP in the thighs, and this finding is in agreement with research conducted by Hoskins and Pollard (2005), demonstrating that the biceps femoris, rectus femoris, and quadriceps femoris muscles are highly exposed to the eccentric load and to a great risk of muscle strain during explosive movements.

Changes in movement biomechanics as a result of exercise-induced DOMS could increase the risk of injury (Fleckenstein et al., 2017). For instance, one precursor for muscle strains is believed to be DOMS (Brockett et al., 2001). According to Woods et al. (2004), muscle strains are the most common lower body injuries among professional soccer players. Previous research has provided evidence that muscle soreness is prevalent after a soccer match, and the content of the training sessions in the 72-hour period after the match must be adjusted to effectively manage the training load (Silva et al., 2018). Kawczyński et al. (2014) reported a significant decrease of pressure pain thresholds (PPT) 24 and 48 hours after a soccer match, which is consistent with the typical occurrence of DOMS.

An accurate identification of DOMSaffected muscles is important for the overall assessment of the psychophysical state for each professional player. One of the most popular tools, the Likert scale, is used to evaluate muscle soreness among athletes (Impellizzeri and Maffiuletti, 2007). However, in an ordinal Likert scale, responses can be rated or ranked, but the distance between them is not measurable, and one cannot assume that it is equidistant even though the numbers assigned to those responses are (Sullivan and Artino, 2013). Therefore, in this study, we used a novel technique in pain assessment, which has not yet been used to assess pain reports in soccer players. There are also more technologically advanced ways of assessing injury or musculoskeletal pain disorders, such as ultrasound scans (Hides and Stanton, 2017), magnetic resonance imaging (Crema et al., 2016), multi-channel surface electromyography (De Mey et al., 2013), and pressure pain algometry (Drew et al., 2016). However, drawbacks of these methods are that scales and questionnaires do not provide the complete view on pain localization and changes. In this study, the pain area and location on a digital body chart provided immediate information about any acute injuries throughout training. A review of the previous pain charts also gives insight as to whether the pain reported continued throughout training. Furthermore, digital pain mapping could be used to identify pain and injury patterns or muscle groups at most risk for DOMS.

A limitation of this study is the low number of participants. Moreover, ideally matching pain intensity for each of the MP, JP, and IP across days would be most insightful and recommended for future studies. Assessing the intensity or using a Likert scale in combination with each pain type report would provide a more complete and accurate record.

\section{Conclusions}

Our findings show MP, JP, and IP are commonly reported by young soccer goalkeepers across a short training period (5 days). The results emphasize the value of assessing the pain location and area clinically and may provide a means to prevent injuries through continuous monitoring of the soccer player. The digital nature of the recordings enables the pre-determined location, size and shape, intensity, and type of pain to be reviewed graphically, processed, and archived as medical data attached to the history of the training and recovery process of an athlete. The convergence between areas of joint or impact pain and typical joint or impact-related injuries in soccer could provide useful information for preventative and documentation purposes in professional athletes. 


\section{References}

Arnason A, Sigurdsson SB, Gudmundsson A, Holme I, Engebretsen L, Bahr R. Risk factors for injuries in football. Am J Sports Med, 2004; 32: 5S-16S

Boudreau SA, Badsberg S, Christensen SW, Egsgaard LL. Digital Pain Drawings: Assessing Touch-Screen Technology and 3D Body Schemas. Clin J Pain, 2016; 32: 139-45

Boudreau SA, Kamavuako EN, Rathleff MS. Distribution and symmetrical patellofemoral pain patterns as revealed by high-resolution 3D body mapping: a cross-sectional study. BMC Musculoskelet Disord, 2017; 18: 160

Brockett CL, Morgan DL, Proske U. Human hamstring muscles adapt to eccentric exercise by changing optimum length. Med Sci Sports Exerc, 2001; 33: 783-90

Carfagno DG, Hendrix JC. Overtraining syndrome in the athlete: current clinical practice. Curr Sports Med Rep, 2014; 13: 45-51

Chamari K, Haddad M, Wong DP, Dellal A, Chaouachi A. Injury rates in professional soccer players during Ramadan. J Sports Sci, 2012; 30 Suppl 1: S93-102

Chatzinikolaou A, Fatouros IG, Gourgoulis V, Avloniti A, Jamurtas AZ, Nikolaidis MG, Douroudos I, Michailidis Y, Beneka A, Malliou P, Tofas T, Georgiadis I, Mandalidis D, Taxildaris K. Time course of changes in performance and inflammatory responses after acute plyometric exercise. J Strength Cond Res, 2010; 24: 1389-98

Crema MD, Guermazi A, Tol JL, Niu J, Hamilton B, Roemer FW. Acute hamstring injury in football players: Association between anatomical location and extent of injury-A large single-center MRI report. J Sci Med Sport, 2016; 19: 317-22

De Mey K, Danneels LA, Cagnie B, Huyghe L, Seyns E, Cools AM. Conscious correction of scapular orientation in overhead athletes performing selected shoulder rehabilitation exercises: the effect on trapezius muscle activation measured by surface electromyography. J Orthop Sports Phys Ther, 2013; 43: 3-10

Drew MK, Lovell G, Palsson TS, Chiarelli PE, Osmotherly PG. Do Australian Football players have sensitive groins? Players with current groin pain exhibit mechanical hyperalgesia of the adductor tendon. J Sci Med Sport, 2016; 19: 784-8

Egsgaard LL, Christensen TS, Petersen IM, Brønnum DS, Boudreau SA. Do Gender-Specific and HighResolution Three Dimensional Body Charts Facilitate the Communication of Pain for Women? A Quantitative and Qualitative Study. JMIR Hum Factors, 2016; 3: e19

Ekstrand J, Hägglund M, Waldén M. Epidemiology of muscle injuries in professional football (soccer). Am J Sports Med, 2011; 39: 1226-32

Ekstrand J, Waldén M, Hägglund M. Risk for injury when playing in a national football team. Scand J Med Sci Sports, 2004; 14: 34-8

Fleckenstein J, Simon P, König M, Vogt L, Banzer W. The pain threshold of high-threshold mechanosensitive receptors subsequent to maximal eccentric exercise is a potential marker in the prediction of DOMS associated impairment. PLoS One, 2017; 12: e0185463

Hägglund M, Waldén M, Bahr R, Ekstrand J. Methods for epidemiological study of injuries to professional football players: developing the UEFA model. Br J Sports Med, 2005; 39: 340-6

Hägglund M, Waldén M, Ekstrand J. Exposure and injury risk in Swedish elite football: a comparison between seasons 1982 and 2001. Scand J Med Sci Sports, 2003; 13: 364-70

Hides JA, Stanton WR. Predicting football injuries using size and ratio of the multifidus and quadratus lumborum muscles. Scand J Med Sci Sports, 2017; 27: 440-447

Hölmich P. Groin injuries in athletes--development of clinical entities, treatment, and prevention. Dan Med J, 2015; 62: B5184

Hootman JM, Dick R, Agel J. Epidemiology of collegiate injuries for 15 sports: summary and recommendations for injury prevention initiatives. J Athl Train, 2007; 42: 311-9

Hoskins W, Pollard H. The management of hamstring injury--Part 1: Issues in diagnosis. Man Ther, 2005; 10: 96-107 
Impellizzeri FM, Maffiuletti NA. Convergent evidence for construct validity of a 7-point likert scale of lower limb muscle soreness. Clin J Sport Med, 2007; 17: 494-6

Jensen J, Holmich P, Bandholm T, Zebis MK, Andersen LL, Thorborg K. Eccentric strengthening effect of hip-adductor training with elastic bands in soccer players: a randomised controlled trial. Br J Sports Med, 2014; 48: 332-8

Kawczyński A, Mroczek D, Frąckiewicz A, Chmura P, Becella L, Samani A, Madeleine P, Chmura J. Effects of two recovery procedures after a football game on sensory and biochemical markers. J Sports Med Phys Fitness, 2014; 54: 394-402

Kirkendall DT, Dvorak J. Effective injury prevention in soccer. Phys Sportsmed, 2010; 38: 147-57

Knoop M, Fernandez-Fernandez J, Ferrauti A. Evaluation of a specific reaction and action speed test for the soccer goalkeeper. J Strength Cond Res, 2013; 27: 2141-8

Kristenson K, Waldén M, Ekstrand J, Hägglund M. Lower injury rates for newcomers to professional soccer: a prospective cohort study over 9 consecutive seasons. Am J Sports Med, 2013; 41: 1419-25

Osgnach C, Poser S, Bernardini R, Rinaldo R, di Prampero PE. Energy cost and metabolic power in elite soccer: a new match analysis approach. Med Sci Sports Exerc, 2010; 42: 170-8

Silva JR, Rumpf MC, Hertzog M, Castagna C, Farooq A, Girard O, Hader K. Acute and Residual Soccer Match-Related Fatigue: A Systematic Review and Meta-analysis. Sports Med, 2018; 48(3): 539-583

Sullivan GM, Artino AR. Analyzing and interpreting data from likert-type scales. J Grad Med Educ, 2013; 5: 541-2

Woods C, Hawkins RD, Maltby S, Hulse M, Thomas A, Hodson A, Football Association Medical Research Programme. The Football Association Medical Research Programme: an audit of injuries in professional football--analysis of hamstring injuries. Br J Sports Med, 2004; 38: 36-41

\section{Corresponding author:}

\section{Adam Kawczyński}

Department of Sport Science,

University School of Physical Education in Wroclaw;

Wrocław, Poland

E-mail: kawczynski.a@gmail.com 